\title{
Apparent bioavailability of isoflavones after intake of liquid and solid soya foods
}

\author{
Adrian A. Franke ${ }^{1 *}$, Leslie A. Ashburn ${ }^{1}$, Kerry Kakazu ${ }^{1}$, Shana Suzuki ${ }^{1}$, Lynne R. Wilkens ${ }^{1}$ \\ and Brunhild M. Halm ${ }^{1,2,3}$ \\ ${ }^{1}$ Natural Products and Cancer Biology Program, Cancer Research Center of Hawaii, 1236 Lauhala Street, Honolulu, HI 96813, USA \\ ${ }^{2}$ Cancer Prevention and Control Program, Cancer Research Center of Hawaii, 1960 East-West Road, Biomedical Sciences C-105, \\ Honolulu, HI 96822, USA \\ ${ }^{3}$ Kapi'olani Medical Center for Women and Children, 1319 Punahou Street, Honolulu, HI 96822, USA
}

(Received 17 December 2008 - Revised 5 March 2009 - Accepted 14 April 2009 - First published online 19 May 2009)

\begin{abstract}
Isoflavone (IFL) intake may provide numerous health benefits, but IFL bioavailability differences among soya foods remains uncertain. Urinary IFL excretion (UIE) was shown to provide a reliable surrogate for systemic IFL exposure and therefore can be used as a measure of 'apparent bioavailability' $(\mathrm{AB})$. We investigated the $\mathrm{AB}$ of IFL in fourteen healthy adults, consuming two liquid and two solid soya foods in a crossover designed study. Volunteers consumed the foods with a self-selected breakfast, which was kept identical for all four soya items (soya nuts, soya milk, soya protein bar and soya protein powder drink in water; average $23.7 \mathrm{mg}$ IFL, $88-96 \%$ glycosides, by HPLC analysis) and collected all urine up to $26 \mathrm{~h}$. Liquid foods showed initially higher UIE values than solid foods, but this difference was considerably reduced or disappeared entirely after $24-26 \mathrm{~h}$. Conclusive AB results were obtained only after $24-26 \mathrm{~h}$; earlier collections were not reliable. At $26 \mathrm{~h}$, adjusted UIE values for daidzein (DE) were $20 \mu \mathrm{mol}$ in the milk and bar and $17 \mu \mathrm{mol}$ for the nut and powder; urinary genistein excretion was the highest in the milk group $(10 \mu \mathrm{mol})$ followed by the nut, bar (both $6 \mu \mathrm{mol})$ and powder groups $(5 \mu \mathrm{mol})$; the UIE for glycitein was the highest for bars $(4 \mu \mathrm{mol})$, followed by powder and nuts $(3 \mu \mathrm{mol})$, and milk $(2 \mu \mathrm{mol})$. DE makes the largest contribution to urinary total IFL. The AB of IFL was found to be variable depending on the analyte and soya food consumed.
\end{abstract}

Isoflavones: Bioavailability: Urine: Soya: Liquid foods: Solid foods

Soya and its isoflavones (IFL) are reported to prevent cancer, heart diseases and other chronic disorders ${ }^{(1-6)}$, especially when the dietary exposure occurs early in life $\mathrm{e}^{(7-10)}$. Similar to the situation with flavonoids, several human studies have established that isoflavonoid glycosides, the main IFL form present in a soya containing diet, taken orally, appear in the circulation as glucuronides and sulphates ${ }^{(11-18)}$. The available evidence suggests that during digestion, isoflavonoid glycosides are hydrolysed mainly by intestinal bacteria, followed by passive diffusion through the mucosa and reconjugation to glucuronides and sulphates on the basolateral side of the enterocyte and/or in the liver ${ }^{(19,20)}$. Gut bacteria play an additional vital role because they also form the major IFL metabolites (dihydrodaidzein, dihydrogenistein, equol (EQ), $O$-desmethylangolensin) and further degrade IFL $^{(21-23)}$.

We and others have shown recently that blood and urine isoflavonoid values, including those in children, are highly correlated, particularly when timing of collection is considered accurately ${ }^{(19,24-30)}$. Since bioavailability is defined based on circulating levels, we suggest the term 'apparent bioavailability' $(\mathrm{AB})$ when using urinary excretion data as surrogate to describe systemic exposure ${ }^{(29,31)}$.
In a variety of studies on IFL bioavailability after soya intake, either men or women (often in one menopausal state) alone $e^{(32-38)}$, solid soya alone ${ }^{(36)}$ or highly processed foods alone $^{(38)}$ was investigated. Despite variabilities, in particular related to the patterns of the individual IFL daidzein (DE), genistein (GE) and glycitein (GLYE), the unifying result of previous investigations was that background diet plays an important role ${ }^{(36)}$. For example, fibre decreases IFL uptake $^{(37)}$ and fat decreases EQ production ${ }^{(39)}$. Additionally, the IFL from liquid soya foods was absorbed more quickly $^{(19,35)}$ and more extensively ${ }^{(40)}$. Aglycons as present in fermented soya products were found to result in higher IFL uptake by some ${ }^{(33,40-42)}$, but not others ${ }^{(19,34,43)}$ including non-distinguishable differences ${ }^{(44,45)}$.

While considerable knowledge exists in experimental settings $(41,43,46,47)$, the uptake efficiency and pharmacokinetic parameters of IFL from various soya foods are little understood in human subjects. By measuring urinary isoflavonoid excretion (UIE), the intent of this research was to find out whether the isoflavonoid exposure differs between different types of soya foods consumed. We aimed to compare liquid (soya milk and soya protein drink referred to as 'milk' and

Abbreviations: AB, apparent bioavailability; DE, daidzein; EQ, equol; GE, genistein; GLYE, glycitein; IFL, isoflavone; UIE, urinary IFL excretion.

* Corresponding author: Dr Adrian A. Franke, fax +1 808586 2970, email adrian@crch.hawaii.edu 
'powder') $v$. solid (soya nuts and soya protein bars referred to as 'nuts' and 'bars') and native $v$. processed soya foods. An important part of the present study was to keep the foods consumed together with the respective study soya item constant in order to avoid confounding effects by the food environment. In addition, we aimed to determine the time frame needed within $26 \mathrm{~h}$ after soya intake to determine IFL excretion accurately considering the biphasic UIE profile ${ }^{(19)}$.

\section{Methods \\ Population}

The University of Hawaii Committee on Human Studies approved the study protocol and consent form. The latter was signed by all participants. In total fourteen participants took part in the study. The subjects recruited were healthy, with no known soya allergies, who did not report antibiotic use within any 4-week period before consuming the study soya food. Each participant consented to donating their full volume of urine immediately before and $2,8,24$, and $26 \mathrm{~h}$ after intake of at least four different soya foods (nuts, milk, health bar and protein drink), which was designed to happen on four separate days, each of them approximately 1-week apart.

Data from urines that were collected with more than $10 \%$ difference to the scheduled time point were omitted. For soya nuts, eleven people correctly completed the 2 and 8-h collections, ten completed the 24-h collection and thirteen completed the up to $26-\mathrm{h}$ collections. For soya milk, eleven participants completed the 2, 8 and 24-h collections, and thirteen completed the up to 26 -h collection correctly. For the soya bar, eleven people correctly collected the 2, 8 and 24-h collections, and all fourteen completed the up to 26-h collections. Finally, for the soya powder drink, nine were able to correctly collect the 2,8 and 24-h collections, with thirteen completing the up to $26-\mathrm{h}$ collections (Table 1 ).

\section{Study procedures}

After emptying their bladders for the spot urine collection, the participants had breakfast with the study soya food and subsequently donated all urine during $0-2,2-8,8-24$ and $24-26-h$ time periods. According to HPLC analysis ${ }^{(48)}$, the serving sizes of the respective soya foods, namely $13.6 \mathrm{~g}$ lightly salted and roasted soya nuts (referred to in text as nuts), $12.7 \mathrm{~g}$ Peanut Pal soya bar (referred to in text as bar) containing as IFL source soya protein, $12.6 \mathrm{~g}$ Strawberry Banana Bliss soya protein powder drink (referred to in text as powder) mixed with water (all from Revival ${ }^{\circledR}$, Physician's Pharmaceuticals, Kernersville, NC, USA) and $95 \cdot 2 \mathrm{~g}$ WestSoy organic unsweetened soya milk (referred to in text as milk; Hain Celestial Group, Boulder, CO, USA) contained on average 23.7 (SD $0.03 \mathrm{mg}$ IFL (Table 2). The soya food was consumed together with a breakfast of the participants' choice (some participants brought their own breakfast). The study staff kept the breakfast exactly the same across each of the 4-5 study days. After an approximately 1-week washout period, the participants repeated the same procedure as described earlier with a different soya food during the following weeks.
Table 1. Participant characteristics and urine collection details (Mean values and standard deviations)

\begin{tabular}{|c|c|c|c|}
\hline & Mean & SD & $n$ \\
\hline Male (\%) & & & 3 \\
\hline Female (\%) & & & 11 \\
\hline BMI $\left(\mathrm{kg} / \mathrm{m}^{2}\right)$ & $21 \cdot 6$ & 1.97 & 14 \\
\hline Age (years) & 39.4 & $10 \cdot 74$ & 14 \\
\hline Asian (\%) & & & 2 \\
\hline Caucasian (\%) & & & 10 \\
\hline Mixed/other (\%) & & & 2 \\
\hline \multicolumn{4}{|l|}{ 2-h Collection } \\
\hline Nuts & $1 \cdot 85^{\star}$ & 0.23 & $11 \dagger$ \\
\hline Milk & $2 \cdot 03^{*}$ & 0.32 & $11 \dagger$ \\
\hline Bar & $1.92^{*}$ & 0.13 & $11 \dagger$ \\
\hline Powder & $1 \cdot 89^{\star}$ & 0.12 & $9+$ \\
\hline \multicolumn{4}{|l|}{ 8-h Collection } \\
\hline Nuts & $7 \cdot 95^{\star}$ & 0.32 & $11 \dagger$ \\
\hline Milk & $8 \cdot 26^{\star}$ & 0.86 & $11 \dagger$ \\
\hline Bar & $7 \cdot 87^{\star}$ & 0.09 & $11 \dagger$ \\
\hline Powder & $7 \cdot 89^{\star}$ & 0.19 & $9 \dagger$ \\
\hline \multicolumn{4}{|l|}{ 24-h Collection } \\
\hline Nuts & $23 \cdot 80^{*}$ & 0.14 & $10 \dagger$ \\
\hline Milk & $24 \cdot 00^{*}$ & 0.36 & $11 \dagger$ \\
\hline Bar & $23 \cdot 86^{\star}$ & 0.11 & $11 \dagger$ \\
\hline Powder & $23 \cdot 92^{*}$ & 0.11 & $9 \dagger$ \\
\hline \multicolumn{4}{|l|}{ 26-h Collection } \\
\hline Nuts & $25 \cdot 87^{\star}$ & 0.14 & $13+$ \\
\hline Milk & $26 \cdot 03^{\star}$ & 0.38 & $13+$ \\
\hline Bar & $25 \cdot 96^{\star}$ & 0.18 & $14 \dagger$ \\
\hline Powder & $25 \cdot 92^{\star}$ & 0.15 & $13+$ \\
\hline
\end{tabular}

Sum of percentage may differ from 100 owing to rounding.

${ }^{\star}$ Mean hours since respective soya intake.

†Total number of participants collecting urine correctly during the given time periods.

Urine containers included approximately $200 \mathrm{mg}$ boric and $100 \mathrm{mg}$ ascorbic acid as preservatives ${ }^{(49)}$. Urine samples were immediately weighed, followed by storage of $2 \mathrm{ml}$ aliquots at $-20^{\circ} \mathrm{C}$; if collected urine needed to be stored longer than $2 \mathrm{~h}$, it was kept chilled in coolers that contained ice packs. Participants completed a validated two-page soya intake and a twenty-six-page diet and health questionnaire ${ }^{(50)}$, and provided information regarding their height and weight. On their worksheets, they recorded time and date of urine collections, food consumption during the study day and the time at which the study food was consumed. Participants avoided eating soya foods for a full $48 \mathrm{~h}$ before and during the $26 \mathrm{~h}$ of the study day. Preliminary data suggested that allowing participants to consume soya food(s) within $24 \mathrm{~h}$ before the baseline urine collection interferes with the study results. We confirmed by questionnaire that the participants had refrained from taking oral antibiotics within 4 weeks before and during their participation, that they had avoided eating any soya products $48 \mathrm{~h}$ before the start of the study, that they had fasted overnight, and that they did not have any gastrointestinal problems before or on the study day.

\section{Urinary isoflavonoid analysis}

DE, GE, GLYE, EQ, O-desmethylangolensin, dihydrogenistein and dihydrodaidzein (the sum of these were calculated as 'Total IFL') were analysed by HPLC with electrospray ionisation (negative mode) tandem mass spectrometry 
Table 2. Isoflavone doses of study soya foods consumed*

\begin{tabular}{|c|c|c|c|c|c|c|c|c|}
\hline Study food $\dagger$ & Daidzein & Glycitein & Genistein & Total isoflavones & Glucosides (\%) & Malonates (\%) & Acetates (\%) & Aglycons (\%) \\
\hline \multicolumn{9}{|l|}{ Nuts } \\
\hline $\mathrm{mg}$ & 11.2 & 1.3 & 11.2 & 23.7 & 34 & 6 & 56 & 4 \\
\hline$\mu \mathrm{mol}$ & 44.1 & 4.6 & $41 \cdot 3$ & $90 \cdot 1$ & & & & \\
\hline \multicolumn{9}{|l|}{ Milk } \\
\hline $\mathrm{mg}$ & 12.4 & 1.3 & 9.7 & 23.4 & 59 & 28 & 8 & 4 \\
\hline$\mu \mathrm{mol}$ & 48.9 & 4.5 & 35.9 & 89.3 & & & & \\
\hline \multicolumn{9}{|l|}{ Bar } \\
\hline $\mathrm{mg}$ & $13 \cdot 3$ & 4.2 & $5 \cdot 7$ & 23.2 & 54 & 8 & 27 & 12 \\
\hline$\mu \mathrm{mol}$ & 52.2 & 14.8 & 21.0 & 88.0 & & & & \\
\hline \multicolumn{9}{|l|}{ Powder } \\
\hline $\mathrm{mg}$ & 14.2 & $4 \cdot 1$ & $6 \cdot 2$ & 24.6 & 57 & 13 & 24 & 7 \\
\hline$\mu \mathrm{mol}$ & $56 \cdot 0$ & 14.6 & $22 \cdot 8$ & 93.5 & & & & \\
\hline
\end{tabular}

Total isoflavone values may deviate from the sum of individual isoflavones owing to rounding.

Total isoflavones = all isoflavones as the sum of native aglycons plus all glycosides.

${ }^{*}$ According to HPLC analysis ${ }^{(48)}$.

† Lightly salted roasted soya nuts $13.6 \mathrm{~g}$ (Revival $\left.{ }^{\circledR}\right)$, unsweetened organic soya milk $95.2 \mathrm{~g}$ (Westsoy Comp.), Peanut Pal bar $12.7 \mathrm{~g}\left(\right.$ Revival $\left.{ }^{\circledR}\right)$ and Strawberry Banana Bliss protein powder $12.6 \mathrm{~g}\left(\right.$ Revival $\left.^{\circledR}\right)$.

(model TSQ Ultra, Thermo, San Jose, CA, USA) similar to our earlier reports ${ }^{(51,52)}$ and as have been detailed most recently ${ }^{(53)}$. Limits of quantitation for all analytes were $1 \mathrm{nM}$ for $\mathrm{DE}$ and GE, $2 \mathrm{nM}$ for EQ and $5 \mathrm{nM}$ for the other analytes. Between-day coefficients of variation ranged between 4 and $18 \%$ for all analytes, while intra-day variation was half or less than that.

Creatinine levels were determined by a clinical autoanalyzer (Roche Cobas MiraPlus; Roche Diagnostics, Indianapolis, IN, USA) using a test kit based on the Jaffé reaction (Randox Laboratories, Crumlin, UK). Isoflavonoid excretion in urine is expressed in nanomoles per hour by adjusting for urine volume and collection times. Baseline urine was converted from nanomoles per milligram creatinine $(\mathrm{nmol} / \mathrm{mg})$ units to $\mathrm{nmol} / \mathrm{h}$ units using hourly creatinine excretion as available from each participant from the timed urine collections ${ }^{(29,54)}$. Instrument calibration was performed daily using stock solutions that were measured for concentrations using absorbance readings as described previously ${ }^{(52)}$.

\section{Calculations}

Since the IFL composition was slightly different between the study foods (Table 2), UIE was adjusted to the IFL doses of nuts; factors applied (to divide measured UIE values by) for milk, bar and powder to that in nuts were for DE $1 \cdot 107$, 1.188 and 1.268 ; for GE $0.866,0.509$ and 0.554 ; for glycitein 1.000, 3.231 and 3.154; and for Tot IFL 0.987, 0.979 and $1 \cdot 038$, respectively. The UIE 2, 8, 24 and $26 \mathrm{~h}$ after soya intake was adjusted for the UIE contribution by the baseline spot urine if the latter had IFL levels $>1000 \mathrm{~nm}$ as described in detailed recently ${ }^{(29,54)}$. This cut-off can be considered conservative because at this level the theoretical amount after $0-2,6-8,8-24$ and $24-26 \mathrm{~h}$ is only $96,217,212$ and $22 \mathrm{nmol}$, respectively, given a creatinine excretion of $1060 \mathrm{mg} / \mathrm{l}$ (equivalent to $55 \mathrm{mg} / \mathrm{h}$ leading to an excretion rate of $52 \mathrm{nmol} / \mathrm{h}$ in our cohort) and a 8 -h half-life of IFL $^{(55)}$. This excretion is negligible compared with the amounts found after soya challenge. Five subjects had levels $<1000 \mathrm{~nm}$ in baseline spot urine, three participants had IFL in the baseline spot urine at levels of $1000-3000 \mathrm{~nm}$ and only one participant had consistently at least one IFL at levels 3000-5000 nM in baseline spot urine, but overall results did not change when this participant was removed from all calculations. The correctness of urine collections was checked by comparing the measured to the theoretically expected urinary creatinine excretion according to the accepted (sex, body weight and age-dependent) values from healthy adults ${ }^{(29,54)}$.

\section{Ethical approval}

The present study was conducted according to the guidelines laid down in the Declaration of Helinski, and all procedures involving human subjects were approved by the University of Hawaii Committee on Human Subjects. Written informed consent was obtained from all subjects.

\section{Statistical analysis}

Paired $t$ tests were performed using Excel 2004 for the Macintosh (Microsoft Inc., Redmond, WA, USA). These tests were performed with log-transformed UIE values to account for the non-normality of distributions. A $P$-value of $<0.05$ was considered suggestive and a $P$-value $<0.05 / 6=0.008$ was considered significant, after Bonferroni correction for the six pairwise multiple comparisons of products at each time point.

\section{Results}

Fourteen subjects were recruited and thirteen completed the collection correctly for the soya foods nuts, milk and bar, whereas fourteen completed the collection correctly for powder during the cumulative up to 26-h time point, respectively. High compliance was observed by individual monitoring of the collections during the day, since participants were all part of our institution. Correct urine collections were also confirmed by the measured creatinine values (data not shown).

There were a total of nine repeat collections for the soya nuts, four for the soya milk, three for the soya bar and two for the powder drink, but only the average within each repeat was used in the present calculations. The mean coefficient of variation of the four types of repeated soya 
products by analyte was DE $19 \%$, GE $29 \%$, GLYE $28 \%$ and total IFL $14 \%$, which can be considered consistent.

The total IFL dose was consistent in all four soya items, namely $23.7,23.4,23.2$ and $24.6 \mathrm{mg}$ for nuts, milk, bar and powder, respectively (mean $=23.7 \mathrm{mg}, \mathrm{CV}=2.6 \%$ ); however, the IFL composition was somewhat different (Table 2). We therefore adjusted all UIE data to doses as present in nuts (see 'Methods' for details), in order to perform an accurate comparison of the $\mathrm{AB}$ between each food item by evaluating each IFL individually. After 2,8 and $24 \mathrm{~h}$ relative to $26 \mathrm{~h}, \mathrm{DE}$ was $10-17,58-69$ and $96-100 \%$ excreted, respectively; for GE, these numbers were 10-17, 49-62 and 85-100 and for GLYE, 7-13, 59-72 and 91-100, respectively (Fig. 1).

In general, the liquid foods, particularly the milk, showed initially higher UIE values than the solid foods, but this difference was much reduced or disappeared entirely after 24 and $26 \mathrm{~h}$. Significant differences $(P<0.01$ by paired $t$ test) in DE excretion between the foods were observed at early collection periods, especially at the 2 -h time point, but these were partially lost for later collections. At the 26-h time point, the milk and bar groups showed urinary $\mathrm{DE}$ excretion of $20 \mu \mathrm{mol}$, while nuts and powder groups showed $17 \mu \mathrm{mol}$, respectively. Significant differences $(P<0.05$ by paired $t$ test) in DE excretions were observed for the groups bar $v$. nuts $(+23 \%)$, milk $v$. powder $(+18 \%)$ and bar $v$. powder $(+18 \%)$. For GE, the pattern changed between the four soya foods much less over time, in fact stayed very similar in the last two collection periods (24 and 26-h
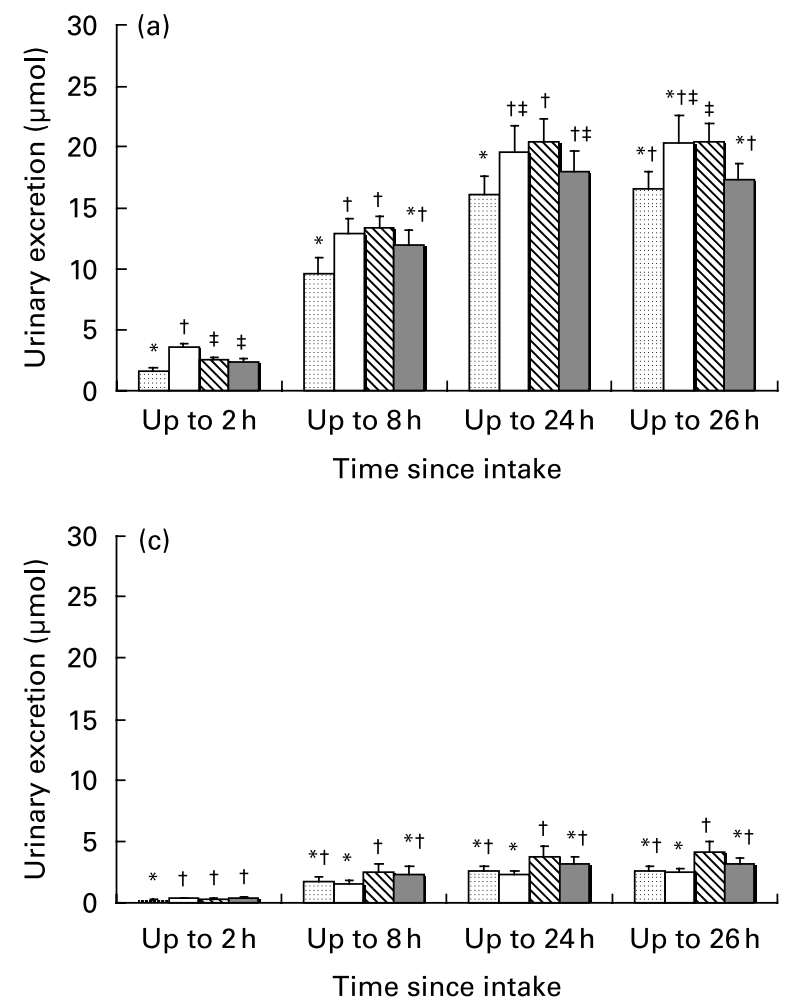

collections). After $26 \mathrm{~h}$, the urinary GE excretion was the highest in the milk group $(10 \mu \mathrm{mol})$, followed by the nut, bar (both $6 \mu \mathrm{mol}$ ) and powder groups $(5 \mu \mathrm{mol})$. The differences were significant $(P<0.05$ by paired $t$ test $)$ between all groups except between nuts and bars, i.e. milk $v$. nuts $+52 \%$, nuts $v$. powder $+32 \%$, milk $v$. bar $+53 \%$, milk $v$. powder $+101 \%$ and bar $v$. power $+31 \%$. The UIE for GLYE was the highest for the bars $(4 \mu \mathrm{mol}) 26 \mathrm{~h}$ after soya intake, followed by powder and nuts $(3 \mu \mathrm{mol})$, and milk $(2 \mu \mathrm{mol})$. The up to 2 -h collection showed significance $(P<0.05$ by paired $t$ test $)$ for milk $v$. nuts $(+52 \%)$, bar $v$. nuts $(+38 \%)$ and powder $v$. nuts $(+52 \%)$. For the up to 8,24 and 26-h collections, only the pair bar $v$. milk showed a significant difference $(+65-67 \% ; P<0.05$ by paired $t$ test).

Total IFL $26 \mathrm{~h}$ after soya intake showed the highest UIE for the bars $(57 \mu \mathrm{mol})$, followed by those of milk $(51 \mu \mathrm{mol})$, powder $(48 \mu \mathrm{mol})$ and nuts $(39 \mu \mathrm{mol})$, respectively. This was significant $(P<0.05$ by paired $t$ test) for the UIE pairs bar $v$. nuts $(+45 \%)$, milk $v$. nuts $(+30 \%)$, powder $v$. nuts $(+23 \%)$ and bar $v$. powder $(+18 \%$; Appendix 1). The same pattern was observed for the up to 8 and 24-h periods, but not for the up to 2-h collection.

The urinary appearance patterns of the metabolites dihydrodaidzein, dihydrogenistein, EQ and $O$-desmethylangolensin are shown in detail in Appendix 1, but the relative short time of specimen collection after soya intake possibly led to an incomplete recovery. The urinary recovery relative to dose $26 \mathrm{~h}$ after soya intake (Table 3 ) showed a similar pattern as described earlier for the individual IFL. Recovery of DE
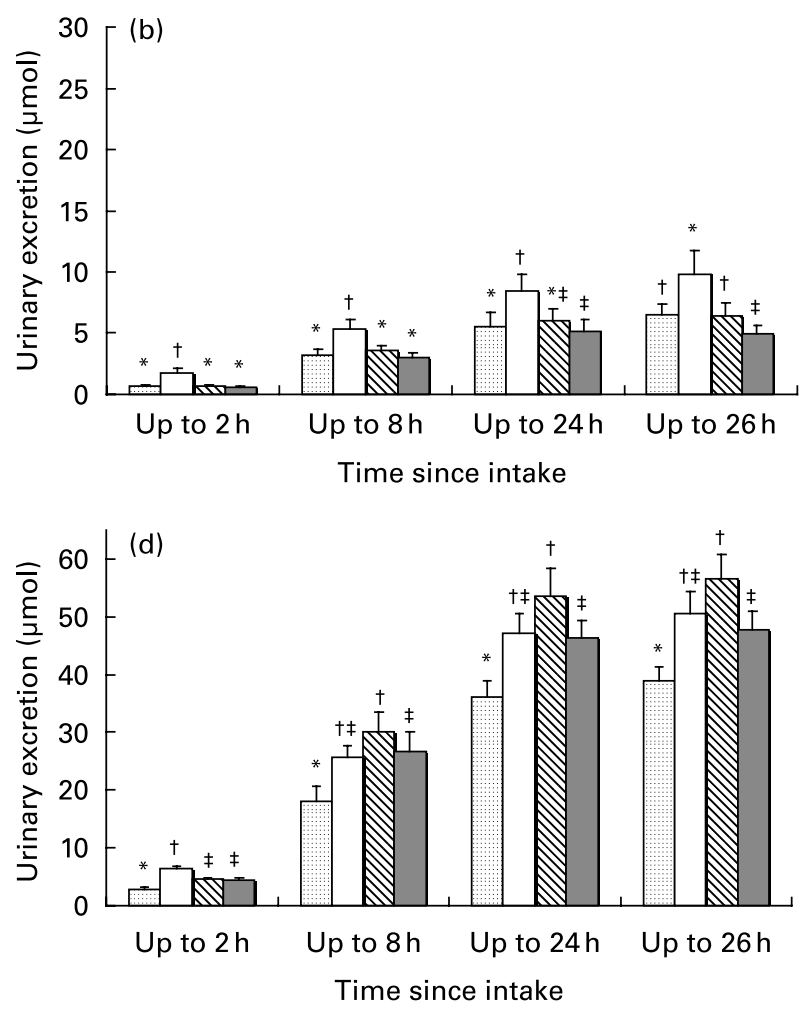

Fig. 1. Urinary excretion of isoflavonoids ((a) daidzein, (b) genistein, (c) glycitein and (d) total isoflavones) over four collection periods after adjustment to dose present in nuts ( $\square$, nut; $\square$, milk; $\mathbb{\nabla}$, bar; $\square$, powder). ${ }^{*}$ Values for individual and total isoflavones within a collection period with different symbols are significantly different $(P<0.05)$; error bars indicate standard error; total isoflavones $=$ daidzein + genistein + glycitein + dihydrodaidzein + dihydrogenistein + equol + O-desmethylangolensin. 
Table 3. Recovery relative to dose in urine collected up to $26 \mathrm{~h}$ after soya food consumption

(Mean values with their standard errors of urinary recovery)

\begin{tabular}{|c|c|c|c|c|c|c|c|c|c|}
\hline & \multicolumn{2}{|c|}{ Nuts } & \multicolumn{2}{|c|}{ Milk } & \multicolumn{2}{|c|}{ Bar } & \multicolumn{2}{|c|}{ Powder } & \multirow[b]{2}{*}{ Significance* $^{\star}$} \\
\hline & Mean & $\mathrm{SE}$ & Mean & SE & Mean & SE & Mean & SE & \\
\hline $\begin{array}{l}\text { Daidzein }+ \text { dihydrodaidzein }+ \text { equol } \\
+ \text { O-desmethyl-angolensin (\%) }\end{array}$ & 62 & 4 & 74 & 4 & 73 & 3 & 61 & 3 & $\mathrm{NM}, \mathrm{NB}, \mathrm{MP}, \mathrm{BP}$ \\
\hline Genistein + dihydrogenistein (\%) & 20 & 3 & 28 & 5 & 19 & 3 & 14 & 2 & $\mathrm{NP}, \mathrm{MB}, \mathrm{MP}, \mathrm{BP}$ \\
\hline Glycitein (\%) & 49 & 5 & 54 & 6 & 56 & 4 & 59 & 4 & NB \\
\hline Total isoflavones (\%) & 43 & 3 & 55 & 4 & 63 & 5 & 54 & 3 & $\mathrm{NM}, \mathrm{NB}, \mathrm{NP}, \mathrm{BP}$ \\
\hline
\end{tabular}

NM, nuts $v$. milk; NB, nuts $v$. bar; NP, nuts $v$. powder, MB, milk $v$. bar; MP, milk $v$. powder; BP, bar $v$. powder.

${ }^{\star}$ Significant difference for food pairs at $P<0.05$ by Student's paired $t$ test of logged values if letters are shown.

and its metabolites were higher in milk (74\%) and bars (73\%) than in nuts $(61 \%)$ and powder $(61 \%)$. The urinary GE recovery was the highest in the milk group ( $28 \%)$, followed by the nut $(20 \%)$, bar (19\%) and powder groups (14\%). Recovery of GLYE was the highest for the powder $(59 \%)$, followed by bars $(56 \%)$, milk (54\%) and nuts (49\%).

\section{Discussion}

It was previously demonstrated that UIE profiles reflect circulating IFL levels accurately ${ }^{(19,28,32)}$ (and also soya intake $^{(25)}$ ) prompting us to use UIE as a reliable surrogate to determine IFL bioavailability. We emphasise that bioavailability is strictly based on measuring levels in the circulation and we therefore refer to $\mathrm{AB}$ when using urinary values. In the present context, it is important to note that the plasma:urine ratio is different between the various IFL (for example different by a factor of 3 comparing DE with GE), but it will remain unchanged within each $\mathrm{IFL}^{(19)}$. Therefore, accurate $\mathrm{AB}$ conclusions can be drawn for each individual IFL when comparing various soya foods or various individuals exposed to or adjusted to the same dose.

In the present study, we examined the UIE of fourteen participants after they had a breakfast, which was kept consistent within each subject during the consumption of all four different soya foods. The soya items were dosed to assure a consistent total IFL exposure. We allowed for approximately 1-week of washout between the consumption of each soya food to avoid interferences. Although a previous study reported no significant difference of UIE when diverse soya foods were consumed ${ }^{(36)}$, we found that the UIE profiles differed significantly between the four soya foods we tested regarding total IFL as well as individual IFL when adjusted to dose. DE was approximately $18 \%$ more bioavailable when consumed from milk or bars relative to nuts or powder. By contrast, GE was the most bioavailable from milk, while nuts and bars were $35 \%$ lower, and powder was $50 \%$ lower. Again different was the sequence for glycitein among the soya foods tested with bars leading, followed by powder (22\% lower), nuts (36\% lower) and milk (40\% lower). This differential IFL bioavailability pattern depending on the type of soya food consumed is in agreement with other studies ${ }^{(32,38)}$. When comparing our urinary recoveries, slight deviations from earlier differences occurred for GE and glycitein owing to the different doses applied in each soya food. By and large though, they followed the described trend even when considering that the urinary recovery data included the metabolites dihydrodaidzein, EQ and $O$-desmethylangolensin with the DE data and dihydrogenistein with the GE data.

In agreement with other studies ${ }^{(32)}$, we found that $\mathrm{DE}$ appeared in much larger amounts in urine than GE, GLYE, or the metabolites (Appendix 1). Therefore, DE is the largest contributor to the total IFL value in urine (in the present study, approximately $40 \%$ ) and predominates the latter value. Consequently, we discourage using the total IFL value as a reliable UIE data point, because it is biased towards DE and suggest considering each IFL individually. This approach will also take into consideration that each IFL has very distinct pharmacologic properties, for example binding to and transactivation of the oestrogen receptors ${ }^{(56)}$.

The present results indicate that specimen collections over at least $24 \mathrm{~h}$ are needed to determine conclusive bioavailability data. Shorter periods are insufficient probably owing to the biphasic IFL appearance pattern in plasma and urine ${ }^{(19,46)}$.

Since the IFL profiles in each of the foods were different, we adjusted the UIE values to the dose present in nuts; this made $\mathrm{AB}$ comparisons between the foods accurate. This was also performed for the total UIE values, although little adjustment was needed since serving sizes were designed to keep the total IFL dose consistent. Some studies have shown that IFL from liquid soya foods such as soya milk are absorbed and excreted more quickly than from solid forms of soya foods ${ }^{(32,40)}$. The present results agree with this finding only for soya milk, but not for the soya protein powder drink. It appears that not all liquid forms of soya are equivalent. This seems to also apply for solid foods because the bars and nuts we tested showed vast differences in $\mathrm{AB}$. The underlying mechanisms for the observed differences in urinary IFL appearance patterns are uncertain, but the matrix of the type of soya food might have had a distinct influence. For example, the considerable fat content of the nuts may have caused a slower uptake ${ }^{(37)}$, while fibre and the solid nature of this food might have decreased general bioaccesibility. Additional factors that could have affected the IFL absorption after soya intake are the intestinal bacteria. IFL absorption will be decreased when these bacteria that hydrolyse the native IFL glycosides to the bioavailable aglycons are impaired. On the other hand, IFL absorption will be increased when bacteria that degrade IFL aglycons during digestion are impaired. This fine line of dynamic changes of IFL bioavailability caused by the gut flora has recently been suggested as an 
explanation for the variable AB of IFL after oral antibiotic therapy ${ }^{(29)}$ and may have also played a role in the findings of the present study. Additional causes for variabilities are intra-individual differences in IFL uptake depending for example on hormonal, immunologic or other factors that play a role during the complex steps of digestion. We tried to address this issue by including repeated challenges with the same soya food in a few of our subjects. More extensive elaborations in this respect would have been desirable, but could not be done owing to budget restrictions and would need to be considered in future studies in order to optimise the robustness of data.

In the present study, the UIE profiles changed significantly between the time periods of urine collection investigated. We therefore realise that urine collections of up to $24-26 \mathrm{~h}$ are necessary in order to obtain accurate values for $A B$ of IFL from soya foods. We observed generally no changes UIE patterns between 24 and 26-h collection periods and therefore assume that longer times of collection will not add significantly more information for the unmetabolised IFL. The reason for less significance between UIE patterns found at $24 v .26 \mathrm{~h}$ are likely due to the lower number of participants in the 24-h time period. An up to 8-h urine collection may give an approximate 'snapshot' of $\mathrm{AB}$, which, however, could change over later times and should therefore not be used as basis for final conclusions. Some of the strengths of the present study include that subjects were highly compliant, health professionals, the washout period of 1 -week between consumption of the different soya foods, utilisation of urinary creatinine to confirm accurate urine collections and several collections of urine during $26 \mathrm{~h}$ in order to determine the appropriate time frame needed to obtain conclusive results about UIE profiles. Similar to others, we kept the background diet consistent ${ }^{(35,41)}$, an important factor since the food matrix has been shown to have an effect of IFL absorption ${ }^{(57)}$. This eliminated possible confounding factors that would have been present if participants were allowed to eat different meals with each soya food. Additional strengths of the present study were the examination of the participants' diet history that assured consistent and healthy dietary behaviours without carnivorous or vegetarian extremes and lack of medication use for at least 1 month before and during the study, particularly antibiotics.

Although our sample size was relatively small and made up primarily of women, we were able to demonstrate significant differences in $\mathrm{AB}$ of IFL. The highly compliant nature of the present study participants, mostly health professionals, possibly contributed to our success. Further studies that include a larger sample size, more equal sex distribution and repeated challenges with the same soya food type are needed to confirm the presented effect of soya food type (liquid $v$. solid; processed $v$. native) on IFL bioavailability.

\section{Acknowledgements}

We thank the participants for their time and cooperation and Physician's Pharmaceuticals, Inc. for partial support of the present study including the donation of soya foods. L. A. A. was responsible for study coordination, urine collection and assistance with data compilation and manuscript preparation,
K. K. for the urine analysis by LCMS, S. S. for the completion of the manuscript, L. R. W. for statistical evaluations, B. M. $\mathrm{H}$. for the study design (she also acted as a consultant in study performance and medical issues) and A. A. F. for the overall supervision of all aspects of the study, securing of research funds and manuscript preparation. We also acknowledge the NIH for instrumentation support S10-RR020890 (there are no conflicts of interest).

\section{References}

1. Yan L \& Spitznagel EL (2005) Meta-analysis of soy food and risk of prostate cancer in men. Int J Cancer 20, 667-669.

2. Yan L \& Spitznagel E (2004) A meta-analysis of soyfoods and risk of breast cancer in women. Int J Cancer Prev 1, 281-293.

3. Rice-Evans C \& Packer L (1998) Flavonoids in Health and Disease. New York: Marcel Dekker.

4. Messina M, Persky V, Setchell KDR, et al. (1994) Soy intake and cancer risk: a review of in vitro and in vivo data. Nutr Cancer 21, 113-131.

5. Stark A \& Madar Z (2002) Phytoestrogens: a review of recent findings. J Pediatr Endocrinol Metab 15, 561-572.

6. Setchell KD \& Lydeking-Olsen E (2003) Dietary phytoestrogens and their effect on bone: evidence from in vitro and in vivo, human observational, and dietary intervention studies. Am J Clin Nutr 78, 593S-609S.

7. Thanos J, Cotterchio M, Boucher BA, et al. (2006) Adolescent dietary phytoestrogen intake and breast cancer risk (Canada). Cancer Causes Control 17, 1253-1261.

8. Fritz WA, Coward L, Wang J, et al. (1998) Dietary genistein: perinatal mammary cancer prevention, bioavailability and toxicity testing in the rat. Carcinogenisis 19, 2151-2158.

9. Shu XO, Jin F, Dai Q, et al. (2001) Soyfood intake during adolescence and subsequent risk of breast cancer among Chinese women. Cancer Epidemiol Biomarkers Prev 10, 483-488.

10. Wu AH, Wan P, Hankin J, et al. (2002) Adolescent and adult soy intake and risk of breast cancer in Asian-Americans. Carcinogenesis 23, 1491-1496.

11. Setchell KD, Brown NM, Zimmer-Nechemias L, et al. (2002) Evidence for lack of absorption of soy isoflavone glycosides in humans, supporting the crucial role of intestinal metabolism for bioavailability. Am J Clin Nutr 76, 447-453.

12. Francis KT (1990) A new single-stage step test for the clinical assessment of maximal oxygen consumption. Phys Ther 70, 734-738.

13. Felgines C, Texier O, Besson C, et al. (2002) Blackberry anthocyanins are slightly bioavailable in rats. $J$ Nutr 132, 1249-1253.

14. Williamson G, Day AJ, Plumb GW, et al. (2000) Human metabolic pathways of dietary flavonoids and cinnamates. Biochem Soc Trans 28, 16-22.

15. Matsumoto H, Inaba H, Kishi M, et al. (2001) Orally administered delphinidin 3-rutinoside and cyanidin 3-rutinoside are directly absorbed in rats and humans and appear in the blood as the intact forms. J Agric Food Chem 49, 1546-1551.

16. Kostic D, White WS \& Olson JA (1995) Intestinal absorption, serum clearance, and interactions between lutein and beta-carotene when administered to human adults in separate or combined oral doses. Am J Clin Nutr 62, 604-610.

17. Sesink ALA, O'Leary KA \& Hollman PCH (2001) Quercetin glucuronides but not glucosides are present in human plasma after consumption of quercetin-3-glucoside or quercetin-4'-glucoside. J Nutr 131, 1938-1941.

18. Walle T, Otake Y, Walle UK, et al. (2000) Quercetin glucosides are completely hydrolyzed in ileostomy patients before absorption. J Nutr 130, 2658-2661. 
19. Franke AA, Custer LJ \& Hundahl SA (2004) Determinants for urinary and plasma isoflavones in humans after soy intake. Nutr Cancer 50, 141-154.

20. Setchell KD (2000) Absorption and metabolism of soy isoflavones-from food to dietary supplements and adults to infants. J Nutr 130, 654S-655S.

21. Setchell KDR, Brown NM \& Lydeking-Olsen E (2002) The clinical importance of the metabolite equol-a clue to the effectiveness of soy and its isoflavones. J Nutr 132, 3577-3584.

22. Atkinson C, Frankenfeld CL \& Lampe JW (2005) Gut bacterial metabolism of the soy isoflavone daidzein: exploring the relevance to human health. Exp Biol Med (Maywood) 230, $155-170$.

23. Bannwart C, Adlercreutz H, Fotsis T, et al. (1984) Identification of $O$-desmethylangolensin, a metabolite of daidzein and of matairesinol, one likely plant precursor of the animal lignan enterolactone in human urine. Finn Chem Lett 4-5, 120-125.

24. Franke AA, Halm BM, Custer LJ, et al. (2006) Isoflavones in breastfed infants after mothers consume soy. Am J Clin Nutr 84, 406-413.

25. Ritchie MR, Morton MS, Deighton N, et al. (2004) Plasma and urinary phyto-oestrogens as biomarkers of intake: validation by duplicate diet analysis. Br J Nutr 91, 447-457.

26. Franke AA, Yu MC, Maskarinec G, et al. (1999) Phytoestrogens in human biomatrices including breast milk. Biochem Soc Trans 27, 308-318.

27. Yamamoto S, Sobue T, Sasaki S, et al. (2001) Validity and reproducibility of a self-administered food-frequency questionnaire to assess the isoflavone intake in a Japanese population in comparison with dietary records and blood and urine isoflavones. J Nutr 131, 2741-2747.

28. Arai Y, Uehara M, Sato Y, et al. (2000) Comparison of isoflavones among dietary intake, plasma concentration and urinary excretion for accurate estimation of phytoestrogen intake. J Epidemiol 10, 127-135.

29. Franke A, Halm B \& Ashburn L (2008) Isoflavones in children and adults consuming soy. Arch Biochem Biophys 476, $161-170$.

30. Grace PB, Taylor JI, Low YL, et al. (2004) Phytoestrogen concentrations in serum and spot urine as biomarkers for dietary phytoestrogen intake and their relation to breast cancer risk in European prospective investigation of cancer and nutritionnorfolk. Cancer Epidemiol Biomarkers Prev 13, 698-708.

31. Franke AA, Halm BM \& Ashburn LA (2008) Urinary isoflavones are increased in adults, but decreased in children, consuming soy when on oral antibiotic therapy. Nutr Cancer 60, 627-635.

32. Faughnan MS, Hawdon A, Ah-Singh E, et al. (2004) Urinary isoflavone kinetics: the effect of age, gender, food matrix and chemical composition. Br J Nutr 91, 567-574.

33. Hutchins AM, Slavin JL \& Lampe JW (1995) Urinary isoflavonoid phytoestrogen and lignan excretion after consumption of fermented and unfermented soy products. J Am Diet Assoc 95, $545-551$.

34. Tsangalis D, Wilcox G, Shah NP, et al. (2005) Bioavailability of isoflavone phytoestrogens in postmenopausal women consuming soya milk fermented with probiotic bifidobacteria. Br J Nutr 93, 867-877.

35. de Pascual-Teresa S, Hallund J, Talbot D, et al. (2005) Absorption of isoflavones in humans: effects of food matrix and processing. $J$ Nutr Biochem 17, 257-264.

36. Xu X, Wang HJ, Murphy PA, et al. (2000) Neither background diet nor type of soy food affects short-term isoflavone bioavailability in women. J Nutr 130, 798-801.

37. Tew BY, Xu X, Wang HJ, et al. (1996) A diet high in wheat fiber decreases the bioavailability of soybean isoflavones in a single meal fed to women. J Nutr 126, 871-877.
38. Anupongsanugool E, Teekachunhatean S, Rojanasthien N, et al. (2005) Pharmacokinetics of isoflavones, daidzein and genistein, after ingestion of soy beverage compared with soy extract capsules in postmenopausal Thai women. BMC Clin Pharmacol 5, 2.

39. Rowland IR, Wiseman H, Sanders TA, et al. (2000) Interindividual variation in metabolism of soy isoflavones and lignans: influence of habitual diet on equol production by the gut microflora. Nutr Cancer 36, 27-32.

40. Cassidy A, Brown JE, Hawdon A, et al. (2006) Factors affecting the bioavailability of soy isoflavones in humans after ingestion of physiologically relevant levels from different soy foods. J Nutr 136, 45-51.

41. Kano M, Takayanagi T, Harada K, et al. (2006) Bioavailability of isoflavones after ingestion of soy beverages in healthy adults. J Nutr 136, 2291-2296.

42. Izumi T, Piskula MK, Osawa S, et al. (2000) Soy isoflavone aglycones are absorbed faster and in higher amounts than their glucosides in humans. J Nutr 130, 1695-1699.

43. Setchell KD, Brown NM, Desai PB, et al. (2003) Bioavailability, disposition, and dose-response effects of soy isoflavones when consumed by healthy women at physiologically typical dietary intakes. $J$ Nutr 133, 1027-1035.

44. Richelle M, Pridmore-Merten S, Bodenstab S, et al. (2002) Hydrolysis of isoflavone glycosides to aglycones by beta-glycosidase does not alter plasma and urine isoflavone pharmacokinetics in postmenopausal women. J Nutr 132, 2587-2592.

45. Maskarinec G, Watts K, Kagihara J, et al. (2008) Urinary isoflavonoid excretion is similar after consuming soya milk and miso soup in Japanese-American women. Br J Nutr 100, 1-6.

46. Zubik L \& Meydani M (2003) Bioavailability of soybean isoflavones from aglycone and glucoside forms in American women. Am J Clin Nutr 77, 1459-1465.

47. Setchell KDR, Faughnan MS, Avades T, et al. (2003) Comparing the pharmacokinetics of daidzein and genistein with the use of 13C-labeled tracers in premenopausal women. Am J Clin Nutr 77, 411-419.

48. Franke AA, Hankin JH, Yu MC, et al. (1999) Isoflavone levels in soy foods consumed by multiethnic populations in Singapore and Hawaii. J Agric Food Chem 47, 977-986.

49. Franke AA \& Custer LJ (1994) High-performance liquid chromatography assay of isoflavonoids and coumestrol from human urine. J Chromatogr B 662, 47-60.

50. Williams AE, Maskarinec G, Hebshi S, et al. (2003) Validation of a soy questionnaire with repeated dietary recalls and urinary isoflavone assessments over one year. Nutr Cancer 47, $118-125$.

51. Blair RM, Appt SE, Franke AA, et al. (2003) Treatment with antibiotics reduces plasma equol concentration in cynomolgus monkeys (Macaca fascicularis). J Nutr 133, 2262-2267.

52. Franke AA, Custer LJ, Wilkens LR, et al. (2002) Liquid chromatographic analysis of dietary phytoestrogens from human urine and blood. J Chromatogr B 777, 43-57.

53. Franke AA, Halm BM, Kakazu K, et al. (2009) Phytoestrogenic isoflavonoids in epidemiologic and clinical research. Drug Test Anal 1, 14-21.

54. Halm B, Ashburn L \& Franke A (2007) Isoflavones from soya foods are more bioavailable in children than adults. Br J Nutr 98, 998-1005.

55. Nielsen IL \& Williamson G (2007) Review of the factors affecting bioavailability of soy isoflavones in humans. Nutr Cancer 57, 1-10.

56. Kuiper GGJM, Carlsson B, Grandien K, et al. (1997) Comparison of the ligand binding specificity and transcript tissue distribution of estrogen receptors a and b. Endocrinology 138, 863-870.

57. Cassidy A (2006) Factors affecting the bioavailability of soy isoflavones in humans. $J$ AOAC Int 89, 1182-1188. 
Appendix 1. Urinary isoflavone excretion adjusted for exposure to doses in soya nuts (Mean values with their standard errors)

\begin{tabular}{|c|c|c|c|c|c|c|c|c|c|}
\hline & \multicolumn{2}{|c|}{ Nuts ( $\mu \mathrm{mol})$} & \multicolumn{2}{|c|}{ Milk ( $\mu \mathrm{mol})$} & \multicolumn{2}{|c|}{ Bar ( $\mu \mathrm{mol})$} & \multicolumn{2}{|c|}{ Powder ( $\mu \mathrm{mol})$} & \multirow[b]{2}{*}{ Significance $†$} \\
\hline & Mean & SE & Mean & SE & Mean & SE & Mean & SE & \\
\hline \multicolumn{10}{|l|}{ Daidzein } \\
\hline baseline $(\mu \mathrm{mol} / \mathrm{h}) \ddagger$ & 0.07 & 0.02 & 0.05 & 0.02 & 0.03 & 0.01 & 0.02 & 0.01 & \\
\hline up to $2 \mathrm{~h}$ & 1.63 & 0.26 & 3.59 & 0.37 & $2 \cdot 52$ & 0.30 & $2 \cdot 35$ & 0.26 & $\mathrm{NM}^{*}, \mathrm{NB}, \mathrm{NP}^{*}, \mathrm{MB}, \mathrm{MP}$ \\
\hline up to $8 \mathrm{~h}$ & 9.65 & $1 \cdot 22$ & 12.99 & $1 \cdot 20$ & $13 \cdot 34$ & 1.00 & 11.98 & $1 \cdot 24$ & $\mathrm{NM}, \mathrm{NB}^{*}$ \\
\hline up to $24 \mathrm{~h}$ & $16 \cdot 11$ & 1.51 & $19 \cdot 62$ & 2.06 & $20 \cdot 49$ & $1 \cdot 84$ & $18 \cdot 02$ & 1.66 & NB \\
\hline up to $26 \mathrm{~h}$ & $16 \cdot 60$ & $1 \cdot 37$ & $20 \cdot 37$ & $2 \cdot 23$ & $20 \cdot 42$ & 1.54 & $17 \cdot 28$ & 1.40 & $\mathrm{NB}, \mathrm{MP}, \mathrm{BP}^{*}$ \\
\hline \multicolumn{10}{|l|}{ Genistein } \\
\hline baseline $(\mu \mathrm{mol} / \mathrm{h}) \ddagger$ & 0.03 & $<0.01$ & 0.03 & 0.01 & 0.02 & 0.01 & 0.01 & $<0.01$ & \\
\hline up to $2 \mathrm{~h}$ & 0.69 & 0.13 & $1 \cdot 75$ & 0.36 & 0.72 & 0.08 & 0.65 & 0.08 & $\mathrm{NM}^{*}, \mathrm{MB}^{*}, \mathrm{MP}^{*}$ \\
\hline up to $8 \mathrm{~h}$ & $3 \cdot 20$ & 0.46 & $5 \cdot 36$ & 0.75 & 3.58 & 0.38 & 3.03 & 0.36 & $\mathrm{NM}^{\star}, \mathrm{MB}, \mathrm{MP}^{\star}$ \\
\hline up to $24 \mathrm{~h}$ & $5 \cdot 55$ & $1 \cdot 11$ & $8 \cdot 41$ & $1 \cdot 36$ & 5.94 & 1.02 & $5 \cdot 15$ & 0.92 & $\mathrm{NM}, \mathrm{NP}, \mathrm{MB}, \mathrm{MP}^{\star}$ \\
\hline up to $26 \mathrm{~h}$ & 6.50 & 0.90 & $9 \cdot 88$ & $1 \cdot 86$ & $6 \cdot 45$ & 1.02 & 4.91 & 0.69 & $\mathrm{NM}, \mathrm{NP}, \mathrm{MB}, \mathrm{MP}^{*}, \mathrm{BP}$ \\
\hline \multicolumn{10}{|l|}{ Glycitein } \\
\hline baseline $(\mu \mathrm{mol} / \mathrm{h}) \ddagger$ & 0.01 & $<0.01$ & 0.01 & $<0.01$ & 0.003 & $<0.01$ & 0.004 & $<0.01$ & \\
\hline up to $2 \mathrm{~h}$ & 0.21 & 0.05 & 0.32 & 0.04 & 0.29 & 0.04 & 0.32 & 0.09 & NM, NB, NP \\
\hline up to $8 \mathrm{~h}$ & $1 \cdot 68$ & 0.42 & $1 \cdot 46$ & 0.25 & $2 \cdot 41$ & 0.78 & $2 \cdot 28$ & 0.65 & $\mathrm{MB}$ \\
\hline up to $24 \mathrm{~h}$ & 2.55 & 0.46 & $2 \cdot 26$ & 0.30 & 3.72 & 0.90 & $3 \cdot 16$ & 0.62 & MB \\
\hline up to $26 \mathrm{~h}$ & 2.58 & 0.38 & 2.44 & 0.26 & 4.07 & 0.88 & $3 \cdot 15$ & 0.43 & MB \\
\hline \multicolumn{10}{|l|}{ Dihydrodaidzein } \\
\hline baseline $(\mu \mathrm{mol} / \mathrm{h}) \ddagger$ & 0.03 & 0.01 & 0.01 & $<0.01$ & 0.01 & $<0.01$ & 0.01 & $<0.01$ & \\
\hline up to $2 \mathrm{~h}$ & 0.02 & 0.01 & 0.03 & 0.01 & 0.02 & 0.01 & 0.01 & $<0.01$ & $\mathrm{BP}^{*}$ \\
\hline up to $8 \mathrm{~h}$ & 1.68 & 0.65 & $1 \cdot 38$ & 0.42 & $1 \cdot 32$ & 0.37 & $1 \cdot 30$ & 0.53 & NM \\
\hline up to $24 \mathrm{~h}$ & $4 \cdot 70$ & $1 \cdot 15$ & $4 \cdot 00$ & 0.81 & $4 \cdot 39$ & 1.07 & $5 \cdot 11$ & 1.49 & \\
\hline up to $26 \mathrm{~h}$ & $5 \cdot 13$ & 1.03 & $5 \cdot 11$ & 1.05 & $5 \cdot 66$ & 1.09 & $5 \cdot 32$ & $1 \cdot 20$ & \\
\hline \multicolumn{10}{|l|}{ Dihydrogenistein } \\
\hline baseline $(\mu \mathrm{mol} / \mathrm{h}) \ddagger$ & 0.01 & $<0.01$ & 0.01 & $<0.01$ & 0.01 & $<0.01$ & 0.004 & $<0.01$ & \\
\hline up to $2 \mathrm{~h}$ & 0.03 & 0.01 & 0.04 & 0.01 & 0.04 & 0.01 & 0.02 & 0.01 & $\mathrm{BP}^{*}$ \\
\hline up to $8 \mathrm{~h}$ & 0.41 & 0.11 & 0.70 & 0.45 & 0.52 & 0.28 & 0.46 & 0.27 & \\
\hline up to $24 \mathrm{~h}$ & 1.50 & 0.70 & 1.67 & 0.87 & $1 \cdot 12$ & 0.50 & 0.89 & 0.31 & \\
\hline up to $26 \mathrm{~h}$ & 1.77 & 0.69 & 1.59 & 0.73 & 1.56 & 0.50 & 0.90 & 0.26 & \\
\hline \multicolumn{10}{|l|}{ O-desmethyl-angolensin } \\
\hline baseline $(\mu \mathrm{mol} / \mathrm{h}) \ddagger$ & 0.02 & $<0.01$ & 0.05 & 0.04 & 0.01 & $<0.01$ & 0.03 & 0.02 & \\
\hline up to $2 \mathrm{~h}$ & 0.02 & 0.01 & 0.08 & 0.06 & 0.02 & 0.01 & 0.02 & 0.01 & \\
\hline up to $8 \mathrm{~h}$ & 0.81 & 0.23 & $1 \cdot 25$ & 0.51 & 1.08 & 0.43 & 0.50 & 0.22 & \\
\hline up to $24 \mathrm{~h}$ & 3.98 & 0.84 & 5.92 & 1.45 & 3.79 & 0.91 & $2 \cdot 13$ & 0.53 & $\mathrm{NM}, \mathrm{NP}, \mathrm{MP}^{*}, \mathrm{BP}$ \\
\hline up to $26 \mathrm{~h}$ & $3 \cdot 74$ & 0.71 & $5 \cdot 75$ & $1 \cdot 31$ & 3.78 & 0.76 & 2.58 & 0.43 & $\mathrm{NM}, \mathrm{MP}, \mathrm{BP}^{*}$ \\
\hline \multicolumn{10}{|l|}{ Equol } \\
\hline baseline $(\mu \mathrm{mol} / \mathrm{h}) \ddagger$ & 0.01 & $<0.01$ & 0.003 & $<0.01$ & 0.005 & $<0.01$ & 0.003 & $<0.01$ & \\
\hline up to $2 \mathrm{~h}$ & 0.01 & 0.01 & 0.01 & $<0.01$ & 0.01 & $<0.01$ & $<0.01$ & $<0.01$ & $\mathrm{NP}, \mathrm{BP}$ \\
\hline up to $8 \mathrm{~h}$ & 0.11 & 0.06 & 0.49 & 0.42 & 0.64 & 0.58 & 0.66 & 0.58 & \\
\hline up to $24 \mathrm{~h}$ & $1 \cdot 23$ & 0.89 & 1.52 & $1 \cdot 00$ & $2 \cdot 20$ & $1 \cdot 35$ & 1.89 & 1.05 & \\
\hline up to $26 \mathrm{~h}$ & $1 \cdot 77$ & 0.92 & $1 \cdot 65$ & 0.96 & 2.02 & $1 \cdot 07$ & $1 \cdot 71$ & 0.78 & \\
\hline \multicolumn{10}{|l|}{ Total isoflavones } \\
\hline baseline $(\mu \mathrm{mol} / \mathrm{h}) \ddagger$ & 0.16 & 0.04 & 0.15 & 0.06 & 0.07 & 0.02 & 0.08 & 0.03 & \\
\hline up to $2 \mathrm{~h}$ & $2 \cdot 77$ & 0.44 & $6 \cdot 30$ & 0.67 & 4.50 & 0.45 & $4 \cdot 32$ & 0.49 & $\mathrm{NM}^{\star}, \mathrm{NB}^{*}, \mathrm{NP}^{*}, \mathrm{MB}, \mathrm{MP}$ \\
\hline up to $8 \mathrm{~h}$ & $18 \cdot 07$ & $2 \cdot 66$ & $25 \cdot 62$ & $2 \cdot 12$ & $30 \cdot 13$ & 3.45 & $26 \cdot 69$ & 3.53 & $\mathrm{NM}^{\star}, \mathrm{NB}^{\star}, \mathrm{NP}, \mathrm{BP}$ \\
\hline up to $24 \mathrm{~h}$ & $36 \cdot 32$ & $2 \cdot 70$ & $47 \cdot 25$ & $3 \cdot 45$ & $53 \cdot 66$ & $4 \cdot 84$ & $46 \cdot 42$ & $3 \cdot 18$ & $\mathrm{NM}, \mathrm{NB}^{*}, \mathrm{NP}, \mathrm{BP}$ \\
\hline up to $26 \mathrm{~h}$ & 38.98 & $2 \cdot 38$ & $50 \cdot 55$ & $3 \cdot 81$ & $56 \cdot 61$ & $4 \cdot 24$ & $47 \cdot 84$ & $3 \cdot 10$ & $\mathrm{NM}, \mathrm{NB}^{\star}, \mathrm{NP}, \mathrm{BP}$ \\
\hline
\end{tabular}

NM, nuts $v$. milk; NB, nuts $v$. bar; NP, nuts $v$. powder; MB, milk v. bar; MP, milk v. powder; BP, bar $v$. powder.

${ }^{\star} P<0.008$ (Bonferroni correction for multiple comparisons $=0.05 / 6$ ).

† Significant difference for food pairs at $P<0.05$ by Student's paired $t$ test of logged values if letters are shown.

$\ddagger$ Calculated from creatinine data $(\mathrm{mg} / \mathrm{h})$ owing to the lack of values for duration and volume of collected urine at baseline (spot urine). 